\title{
Growth and Physiological Responses of Quercus acutissima Seedling under Drought Stress
}

\author{
Hyemin Lim, Jun Won Kang, Solji Lee, Hyunseok Lee, Wi Young Lee* \\ Department of Forest Genetic Resources, National Institute of Forest Science, Suwon 16631, Korea
}

\begin{abstract}
In this study, Quercus acutissima seedlings were subjected to drought for 30 days then analyzed to determine their response to water deficit. The growth phenotype, chlorophyll fluorescence response, fresh weight, dry weight, photosynthetic pigment levels, soluble sugar content, and malondialdehyde (MDA) were measured to evaluate the effects of drought on plant growth and physiology. The growth phenotype was observed by infrared (IR) digital thermal imaging after 30 days of drought treatment. The maximum, average, and minimum temperatures of drought-treated plant leaves were $1-2^{\circ} \mathrm{C}$ higher than those of the control. In contrast, the fresh and dry weights of the dehydrated leaves were generally lower than those of the control. There were no significant differences between treatments in terms of chlorophyll $a$, chlorophyll $b$, total chlorophyll, and carotenoid levels. Nevertheless, for the drought treatment, the $F_{v} / F_{m}$ and $F_{v} / F_{o}$ ratios (chlorophyll fluorescence response) were lower than those for the control. Therefore, photosynthetic activity was lower in the dehydrated plants than the control. The drought-stressed Q. acutissima S0536 had lower soluble sugar (glucose and fructose) and higher MDA levels than the controls. These findings may explain the early growth and physiological responses of $Q$. acutissima to dehydration and facilitate the selection of drought-resistant tree families.
\end{abstract}

Keywords Quercus acutissima, Drought, Water deficit, Stress, Photosynthetic response

\section{INTRODUCTION}

To improve their chances of survival, plants respond to various abiotic stressors such as salt, osmotic effects, heat, cold, and drought (Bray 1997). Soil water deficit is a major factor limiting plant survival and growth (Cattivelli et al. 2008). Climate change has aggravated plant drought stress by prolonging dry periods, reducing water availability, and increasing water resource variability (IPCC 2007). Desertification is increasing at the rate of $1.2 \times 10^{7}$ ha/year as a consequence of excessive pasturing, forest damage, and inappropriate soil and water management. Currently, 1.5 billion people in more than 100 countries are directly affected by desertification, damaging $\sim 41 \%$ of the earth's surface (Reynolds et al. 2007). Stomatal opening, cell division, growth inhibition, and photosynthetic rate reduction occur in plants subjected to drought (Shinozaki and Yamaguchi-Sinozaki 2007). Drought also induces secondary stresses such as metabolic and photosynthetic injuries. In extreme cases, it causes plants to wither. The seedling stage is particularly sensitive to environmental conditions such as atmospheric temperature and soil moisture and nutrient levels (Danby and Hik 2007). The short-term physiological and growth properties of seedlings after germination or transplantation influence their survival and growth rates. Therefore, basic research is required in the area of the response of seedlings to drought stress (Sung et al. 2011).

The genus Quercus (oaks; Fagaceae) includes species and populations with a wide range of drought tolerances and adaptations to dehydration stress (Abrams 1990; Ponton et al. 2002; Tyler et al. 2006; Roussel et al. 2009).

Received November 10, 2017; Revised November 21, 2017; Accepted November 21, 2017; Published December 1, 2017

*Corresponding author Wi Young Lee, lwy20@korea.kr, Tel: +82-31-290-1000, Fax: +82-31-290-1008 
Oak trees constitute $67 \%$ of the broadleaf tree species in Korea. They are concentrated mainly in the southern regions of the country (Kim et al. 1981; Korea Forest Research Institute 1996). Acorns readily germinate and oaks are highly productive in degraded woodlands (Kwon et al. 2002). For these reasons, they dominate Korean forests. The present study used seedlings of Quercus acutissima, the predominant natural broadleaf tree species in Korea, to determine seedling growth and physiological response to drought stress.

\section{MATERIALS AND METHODS}

\section{Plant materials and drought treatment}

Seeds of S0536 (plus tree in Jeonbug) and S012 (plus tree in Gangwon) families were collected in a seedling seed orchard of Quercus acutissima and seedlings were used in this study. In April 2017, seeds were sown in a greenhouse. Thirty days after sowing, uniform plantlets were selected, transferred to flower pots, and raised in a greenhouse. Thirty healthy plants were randomly selected from each treatment group. Plants were watered to a soil moisture level of $40 \%$ one day before the drought treatment. The plants were then deprived of water for 30 days and observed during this time. Soil moisture was measured every other day using a moisture probe (ICT International Pty. Ltd., Armidale, NSW, Australia).

\section{Measurement of chlorophyll fluorescence and IR thermal imaging}

The chlorophyll fluorescence response was measured by the Kautsky induction method (Kautsky and Hirsch 1931) using a portable Handy Fluorcam (Photon System Instruments Ltd., Brno, Czech Republic). Starting at 10 days after drought initiation, ten plants were randomly selected from each treatment group every 4 days. To induce chlorophyll fluorescence, leaves were adapted to the dark by blocking light for 15 minutes followed by irradiation with $1,500 \mu \mathrm{mol} \cdot \mathrm{m}^{-2} \cdot \mathrm{s}^{-1}$ for 5 seconds. The fluorescence variables $F_{o}, F_{m}, F_{v} / F_{o}$, and $F_{v} / F_{m}$ were measured and analyzed. Leaf temperatures were determined by measuring infrared (IR) digital images 30 days after the onset of drought using a Fluke TiX560 Thermal Imager (Fluke Corp., Everett, WA, USA).

\section{Measurement of the chlorophyll content}

The chlorophyll content was determined according to the method of Sibley et al. (1996). From each treatment, 0.1 $\mathrm{g}$ fresh samples were taken in triplicate, homogenized thoroughly with dimethyl formamide (DMF), and centrifuged at $10,000 \times g$ for 10 minutes at $4^{\circ} \mathrm{C}$. The supernatant was used as the chlorophyll source. The chlorophyll levels were determined by reading the supernatant absorbances at $645 \mathrm{~nm}$ and $663 \mathrm{~nm}$ with a UVVis spectrophotometer. The chlorophyll contents and their means were calculated as follows for each plant and treatment:

$$
\begin{aligned}
& \text { Chlorophyll } a=12.7 * \text { A644nm }-2.79 * \text { A647nm } \\
& \text { Chlorophyll } b=20.7 * \text { A647nm }-4.62 * \text { A664nm } \\
& \text { Total chlorophyll }=\text { Chlorophyll } a+\text { Chlorophyll } b \\
& =17.9 * \mathrm{~A} 647 \mathrm{~nm}+8.08 * \mathrm{~A} 664 \mathrm{~nm} \\
& \text { Carotenoids }=(1000 * \mathrm{~A} 470 \mathrm{~nm}-1.82 \mathrm{chl} \mathrm{a}- \\
& 85.02 \mathrm{chl} \mathrm{b}) / 198
\end{aligned}
$$

(A, absorbance; pigment concentration in $\mathrm{mg} / \mathrm{g}$ fresh weight (FW))

\section{Extraction and measurement of soluble sugar}

Glucose, fructose, and sucrose were extracted from the leaves according to the method of Lu and Sharkey (2004). Samples of $0.1 \mathrm{~g}$ leaves were ground to a fine powder in liquid nitrogen. The powder was extracted in $1 \mathrm{~mL} \mathrm{80 \%}$ ethanol $(\mathrm{v} / \mathrm{v})$ at $80^{\circ} \mathrm{C}$ for 30 minutes. Following centrifugation, the supernatants were transferred to new tubes. The pellets were re-extracted with $1 \mathrm{~mL} 80 \%$ ethanol (v/v) at $80^{\circ} \mathrm{C}$ for 30 minutes then recentrifuged. The supernatants were combined with those from the previous extraction and evaporated in a concentrator. The extracts were resuspended in $500 \mu \mathrm{L} \mathrm{H}_{2} \mathrm{O}$ and used for measuring the soluble sugar content. Aliquots of this suspension were enzymatically hydrolyzed according to the methods of Walters et al. (2004). The sugar concentrations were determined enzymatically using a method described by Stitt et al. (1989) and a SpectraMax (Molecular Devices, Sunnyvale, CA, USA). 


\section{Measurement of malondialdehyde}

From each treatment, $0.1 \mathrm{~g}$ leaves were harvested in triplicate and extracted with a buffer consisting of $20 \%$ TCA (w/v) and $0.5 \%$ thiobarbituric acid (TBA) (w/v) followed by warming at $95^{\circ} \mathrm{C}$ for 30 minutes. The reaction was terminated by placing the mixture on ice for 30 minutes then centrifuging it at $12,000 \times g$ for 10 minutes. The absorbance of the supernatant was read at $532 \mathrm{~nm}$ using a spectrophotometer. The MDA content was derived according to the method of Heath and Packer (1968).

\section{RESULTS}

\section{Growth phenotypic analysis of $Q$. acutissima seedlings to drought treatment}

Quercus acutissima S0536 and S012 family seeds were sown in soil. After more than 3 months of growth, the seedlings were subjected to drought treatment for 30 days. The moisture content of the soil subjected to drought was compared to that of the control during the drought treatment period (Fig. 1A). After 10 days of drought treatment, the soil moisture content decreased to less than
$10 \%$, and decreased to less than $1 \%$ after 30 days.

Leaf temperature is a function of transpiration and reflects plant physiological activity. According to the infrared digital image, the S0536 control plants had maximum, average, and minimum temperatures of $22.7^{\circ} \mathrm{C}$, $21.4^{\circ} \mathrm{C}$, and $20.0^{\circ} \mathrm{C}$, respectively. The maximum, average, and minimum temperatures of the drought-treated plants were $23.7^{\circ} \mathrm{C}, 22.4^{\circ} \mathrm{C}$, and $21.6^{\circ} \mathrm{C}$, respectively. The maximum, average, and minimum temperatures of the S012 control trees plants were $23.9^{\circ} \mathrm{C}, 21.8^{\circ} \mathrm{C}$, and $20.4^{\circ} \mathrm{C}$, respectively, and the maximum, average, and minimum temperatures of the drought-treated plants were $23.8^{\circ} \mathrm{C}$, $22.5^{\circ} \mathrm{C}$, and $21.7^{\circ} \mathrm{C}$, respectively. Both S0536 and S012 showed maximum, average, and minimum temperature increases of $1-2^{\circ} \mathrm{C}$ in drought-treated plants relative to their respective controls (Fig. 2).

To evaluate the growth of $Q$. acutissima seedlings subjected to drought stress, shoot heights were measured on the last (30th) day of drought treatment (Fig. 1B). There were no significant differences in the shoot heights of drought-treated S0536 and S012 trees compared to their respective controls. The dry weight is closely correlated with the seedling root collar diameter. Both the dry weight and root collar diameter significantly influence seedling
A

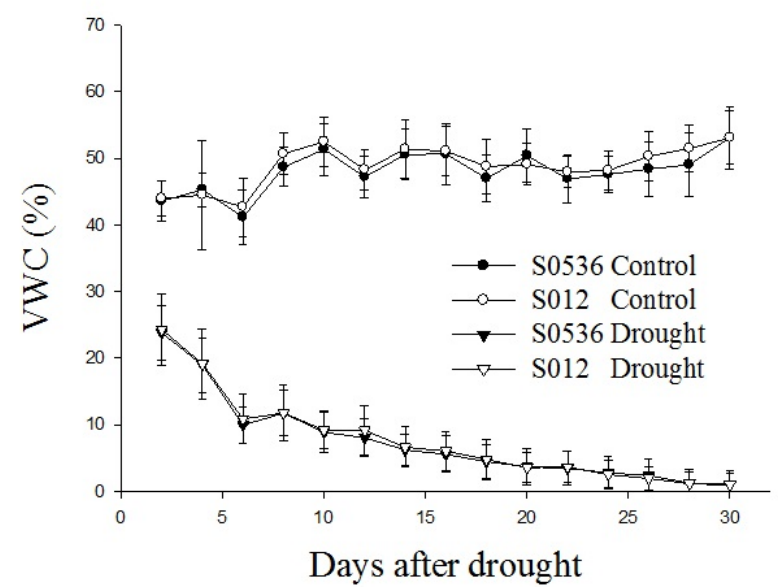

B

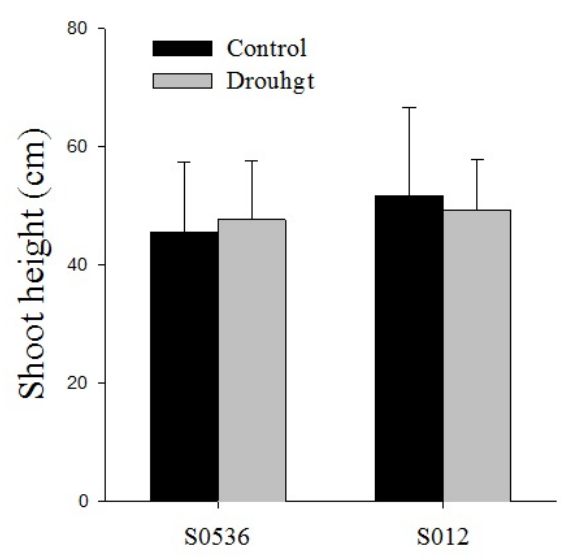

Fig. 1. (A) Volumetric water content in the soil of the control- and drought-treated plant pots. Soil moisture was measured every 2 days for 30 days. The control plants were watered throughout the experiment. (B) Effect of drought on shoot height of Quercus acutissima S0536 and S012 family seedlings. Values are means \pm SD $(n=19)$. No significant difference ( $t$ test) between the control family and the drought-treated family seedlings. 


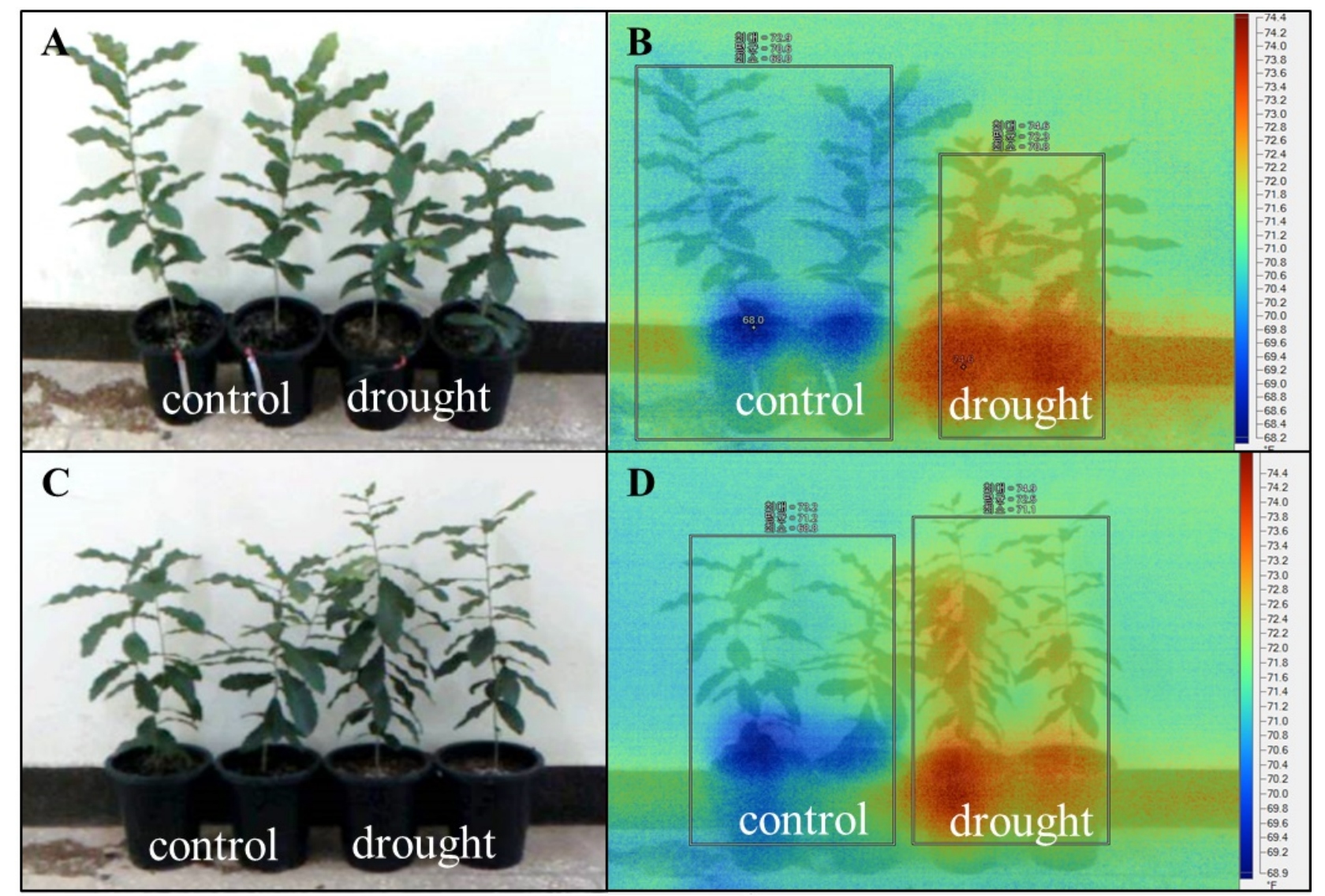

Fig. 2. Growth phenotypes of Quercus acutissima S0536 and S012 family seedlings subjected to drought (A, C). Control plants (left) and drought-treated plants (right) after 30 days. (B, D) Infrared thermal images. (A, B) Q. acutissima S0536 family seedlings. (C, D) Q. acutissima S012 family seedlings.

Table 1. Growth of Qurercus acutissima after drought treatment.

\begin{tabular}{|c|c|c|c|c|c|c|c|c|}
\hline \multirow{2}{*}{ Treatment } & & \multicolumn{3}{|c|}{ Fresh weight $(\mathrm{g} / \text { plant })^{\mathrm{z})}$} & \multicolumn{4}{|c|}{ Dry weight $(\mathrm{g} / \text { plant })^{\mathrm{z})}$} \\
\hline & & Total & Aerial part & Root & Total & Aerial part & Root & $\mathrm{S} / \mathrm{R}$ ratio \\
\hline Control & S0536 & $23.8 \pm 7.4$ & $16.9 \pm 5.4$ & $6.9 \pm 2.6$ & $11.6 \pm 3.6$ & $7.9 \pm 2.5$ & $3.7 \pm 1.4$ & $2.2 \pm 0.6$ \\
\hline Drought & S0536 & $21.8 \pm 2.9$ & $15.8 \pm 2.6$ & $5.9 \pm 1.2$ & $10.5 \pm 2.6$ & $8.0 \pm 1.6$ & $3.1 \pm 0.6^{*}$ & $2.7 \pm 0.7 *$ \\
\hline Control & S012 & $29.0 \pm 11.0$ & $19.0 \pm 7.8$ & $10.0 \pm 3.9$ & $12.3 \pm 4.5$ & $8.4 \pm 3.4$ & $4.0 \pm 1.4$ & $2.2 \pm 0.7$ \\
\hline Drought & S012 & $20.9 \pm 4.0^{* *}$ & $14.1 \pm 3.3^{* *}$ & $6.8 \pm 1.6^{* *}$ & $10.4 \pm 2.4 *$ & $7.1 \pm 1.9$ & $3.4 \pm 0.8^{*}$ & $2.2 \pm 0.5$ \\
\hline
\end{tabular}

${ }^{\mathrm{z})}$ Values are means $\pm \mathrm{SD}(\mathrm{n}=20)$; The asterisks indicate a significant difference $(t$ test; $* P<0.05, * * P<0.01)$ between the control family and the drought-treated family seedlings.

survival and growth (Switzer and Nelson 1963; Ritchie 1984). The plants were divided into shoots and root parts for the fresh and dry weight measurements. Droughttreated S0536 and S012 seedlings had lower fresh and dry root and shoot weights than their control counterparts control (Table 1).

\section{Chlorophyll fluorescence response}

The photochemical efficiency of photosystem (PS) II measured in an $F_{v} / F_{m}$ state did not significantly differ from that of the control for the first 25 days of drought treatment. The $\mathrm{F}_{\mathrm{v}} / \mathrm{F}_{\mathrm{m}}$ remained at $\sim 0.8$. During this period, neither 
$F_{v} / F_{m}$ nor $F_{v} / F_{o}$ significantly differed, suggesting a lack of drought stress in any of the plants. Nevertheless, $F_{v} / F_{m}$ significantly decreased to $<0.7$ after 30 days of drought treatment (Fig. 3A and 3C). The potential photosynthetic ability of PSII $\left(\mathrm{F}_{\mathrm{v}} / \mathrm{F}_{\mathrm{o}}\right)$ showed a similar pattern to that of $F_{v} / F_{m}$ (Fig. 3B and 3D). In general, when $F_{v} / F_{m}$ is $<0.8$, the PSII reaction core is damaged or inactive (Björkman and Demmig 1987). Thirty days of drought treatment reduced $\mathrm{F}_{\mathrm{v}} / \mathrm{F}_{\mathrm{m}}$, which is indicative of drought stress (Kriedemann et al. 1985). It also decreased $F_{v} / F_{o}$, which reflects the size and the density of the PSII active reaction core. The decline in PSII activity, then, could be the result of moisture deficiency (Sagardoy et al. 2009; Jain et al. 2010).

\section{Analysis of the leaf chlorophyll content}

The leaf chlorophyll content is correlated with photosynthetic activity, and chlorophyll levels are affected by stress. The chlorophyll content in drought-treated S0536 and S012 did not significantly differ from that of the controls (Table 2). Furthermore, the total chlorophyll,
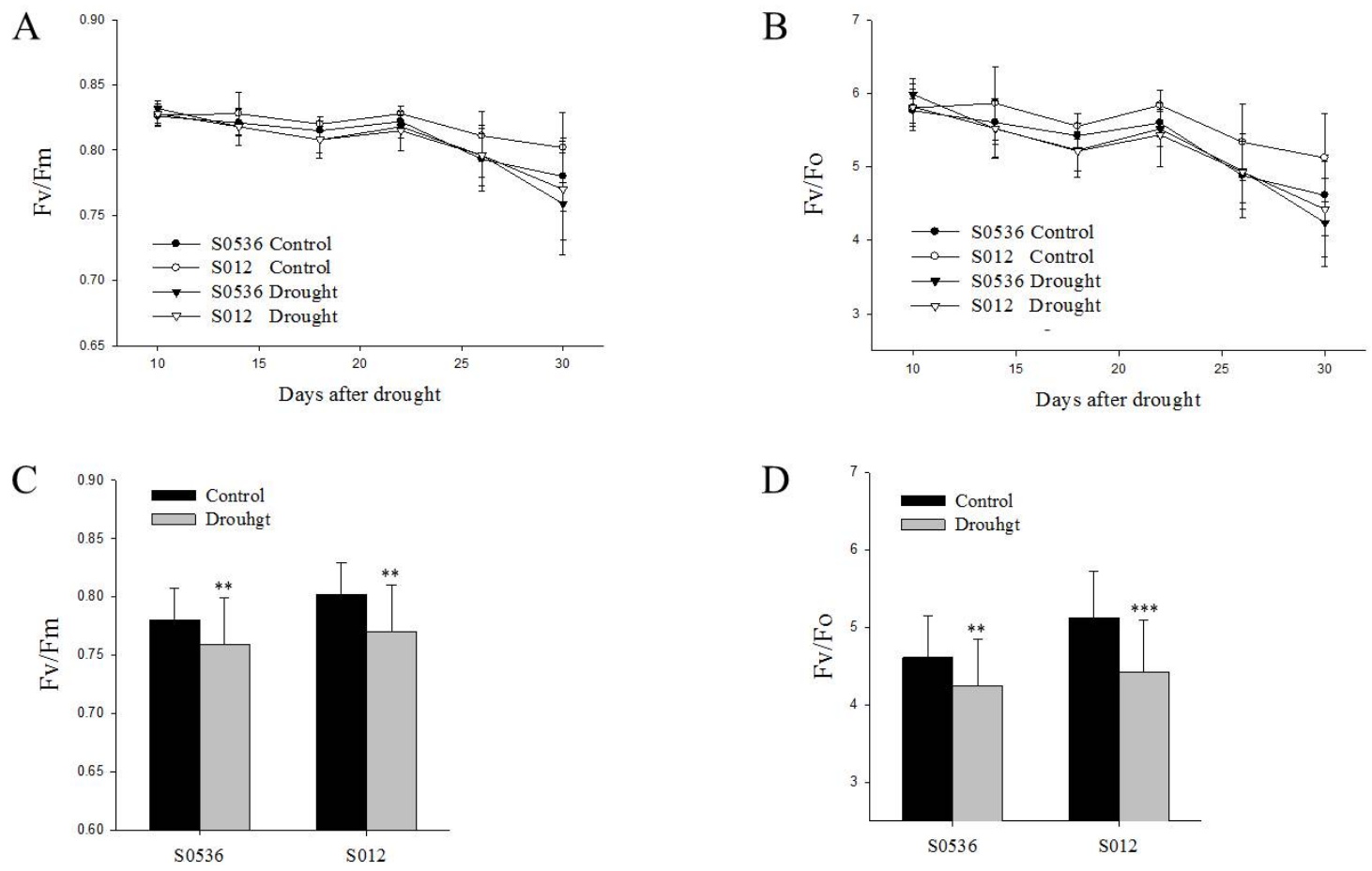

Fig. 3. Effects of chlorophyll a fluorescence in Quercus acutissima seedlings subjected to drought. (A) $F_{v} / F_{m}$ after 30 days. (B) $F_{v} / F_{o}$ after 30 days. (C) $F_{v} / F_{m}$ after 30 days drought. (D) $F_{v} / F_{o}$ after 30 days drought. Values are means \pm $\mathrm{SD}$ of 10 independent measurements. The asterisks indicate a significant difference $(t$ test; $* * P<0.01, * * * P<$ 0.001 ) between the control family and the drought-treated family seedlings.

Table 2. Effects of drought-treated on photosynthetic pigments in Qurercus acutissima seedlings.

\begin{tabular}{|c|c|c|c|c|c|c|c|}
\hline \multirow{2}{*}{ Treatment } & & \multicolumn{4}{|c|}{$\mathrm{mg} / \mathrm{g} \mathrm{FW}$} & \multirow{2}{*}{ Chl a/b ${ }^{z)}$} & \multirow{2}{*}{$\mathrm{Chl} / \mathrm{Car}^{\mathrm{z})}$} \\
\hline & & Chl a & Chl b & Total Chl & Carotenoids & & \\
\hline Control & S0536 & $5.99 \pm 0.55$ & $3.26 \pm 0.22$ & $9.25 \pm 0.76$ & $0.62 \pm 0.09$ & $1.84 \pm 0.07$ & $15.12 \pm 1.95$ \\
\hline Drought & S0536 & $5.79 \pm 0.31$ & $3.35 \pm 0.20$ & $9.14 \pm 0.39$ & $0.61 \pm 0.08$ & $1.73 \pm 0.13$ & $15.20 \pm 2.22$ \\
\hline Control & S012 & $5.50 \pm 0.32$ & $3.17 \pm 0.18$ & $8.67 \pm 0.50$ & $0.48 \pm 0.01$ & $1.73 \pm 0.01$ & $17.96 \pm 1.12$ \\
\hline Drought & S012 & $6.53 \pm 0.43^{*}$ & $3.48 \pm 0.18$ & $10.01 \pm 0.58^{*}$ & $0.79 \pm 0.08 * *$ & $1.88 \pm 0.09 *$ & $12.75 \pm 1.21^{* *}$ \\
\hline
\end{tabular}

${ }^{\mathrm{z})}$ Values are means $\pm \mathrm{SD}(\mathrm{n}=5)$; The asterisks indicate a significant difference $(t$ test; $* P<0.05, * * P<0.01)$ between the control family and the drought-treated family seedlings. 
carotenoid, chlorophyll $a$ : chlorophyll $b$, and the chlorophyll: carotenoid in the drought-treated S0536 and S012 did not significantly differ from those of the controls. According to previous studies, the chlorophyll content may decrease or increase in response to changes in the external environment (Zhao and Liu 2009). The results of the present experiment indicated that photosynthetic pigment levels in $Q$. acutissima seedlings were not significantly affected by drought.

\section{Soluble sugar and MDA levels in $Q$. acutissima seedlings}

To investigate the effect of drought treatment on the carbon metabolite contents of the plants, the glucose, fructose, and sucrose contents were investigated. The levels of glucose, fructose, and sucrose levels in $Q$. acutissima seedlings were measured to determine the effects of drought on carbon partitioning. The glucose contents in the drought-treated seedlings were slightly lower than those in the control plants (Fig. 4A). There were only minor differences in the fructose and sucrose levels in the drought-treated seedlings relative to the controls (Fig. 4B and 4C). The photosynthetic activity and photoassimilate conversion to sugars were slightly more active and efficient in the leaves of the control plants than in those of the drought-stressed seedlings (Cho et al. 2012).

The MDA content was used as an index of membrane lipid peroxidation and tissue damage induced by drought stress. After the drought treatment, the MDA levels in the leaves of drought-treated S0536 and S012 were $14.5 \%$ and $4.1 \%$ higher than those in their respective controls (Fig. 4D). The relative increase in MDA content in drought-
A

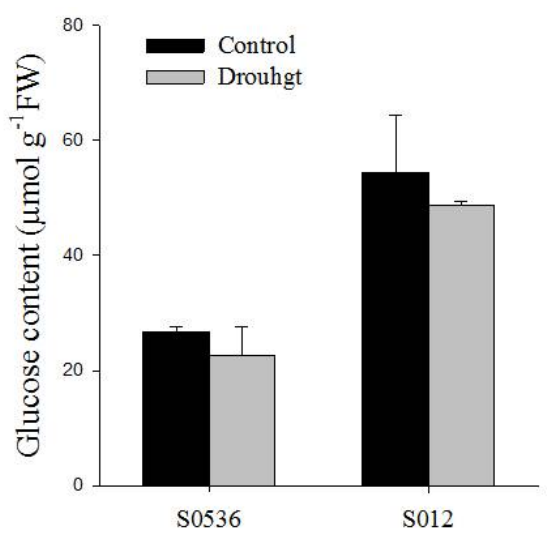

C

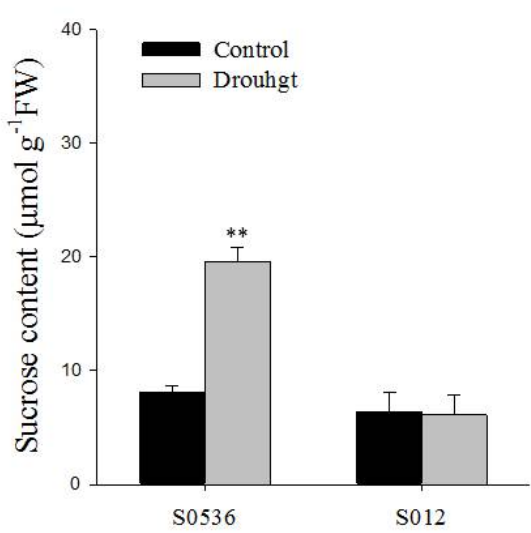

B

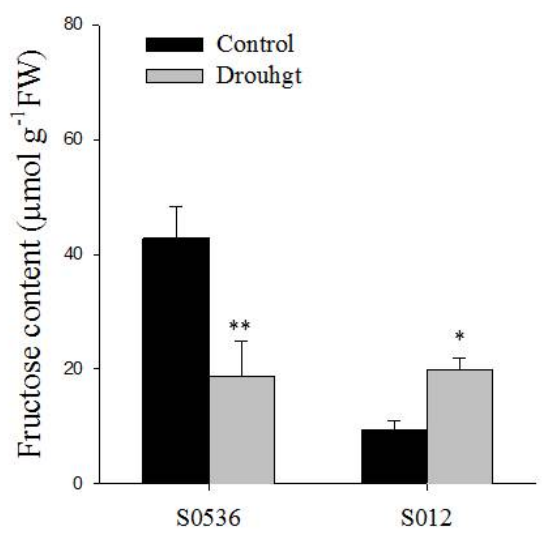

D

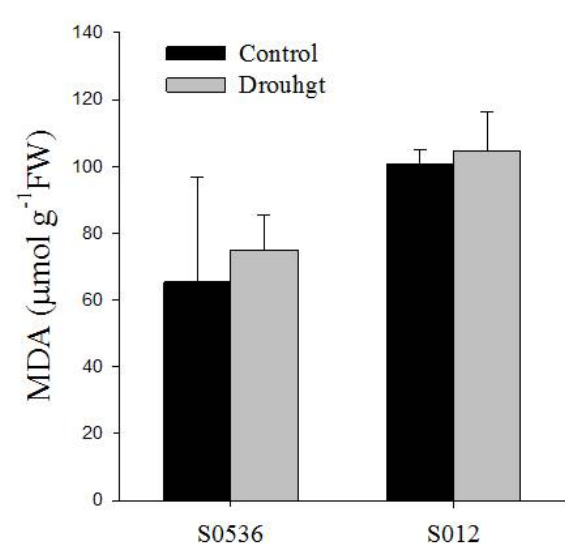

Fig. 4. Effects of the carbohydrate and malondialdehyde in Quercus acutissima seedlings subjected to drought. (A) Glucose. (B) Fructose. (C) Sucrose. (D) Malondialdehyde (MDA) content. Values are means \pm SD of three independent measurements. The asterisks indicate a significant difference $\left(t\right.$ test; $\left.{ }^{*} P<0.05,{ }^{* *} P<0.01\right)$ between the control family and the drought-treated family seedlings. 
stressed seedlings indicates that they were physiologically damaged by the drought treatment, and the oxidative injury was more severe in S0536 than in S012.

\section{DISCUSSION}

Two seed families of the representative broadleaf $Q$. acutissima were subjected to drought treatment for 30 days and compared to their control plants. Photosynthesis is a key primary metabolic process and plays a major role in plants response to dehydration (Chaves et al. 2003). The drought-treated seedlings showed increases in leaf temperature and decreases in $F_{v} / F_{m}$, which is a measure of chlorophyll fluorescence $F_{v} / F_{m}$ value of less than 0.8 suggests a damaged or inactive photosystem II reaction core (Björkman and Demmig 1987). Such a reduction in photosystem II activity could be the result of moisture deficiency from drought treatment. Moreover, seedlings subjected to drought stress had lower soluble sugar content and higher MDA levels than the controls. Although the seedling stage is usually sensitive to environmental conditions, $Q$. acutissima did not show significant changes after 30 days drought treatment. These results may assist in the understanding of the initial growth and physiological responses of $Q$. acutissima under drought stress and facilitate the selection of drought-resistant tree families.

\section{REFERENCES}

Abrams MD. 1990. Adaptations and responses to drought in Quercus species of North America. Tree Physiology 7: 227-238.

Björkman O, Demmig B. 1987. Photon yield of O2 evolution and chlorophyll fluorescence characteristic at $77 \mathrm{~K}$ among vascular plant of diverse origins. Planta 170: 489-504.

Bray EA. 1997. Plant responses to water deficit. Trends Plant Sci. 2: 48-54.

Cattivelli L, Rizza F, Badeck FW, Mazzucotelli E, Mastrangelo AM, Francia E, et al. 2008. Drought tolerance improvement in crop plants: an integrated view from breeding to genomics. Field Crops Res. 105: 1-14.
Chaves MM, Maroco JP, Pereira JS. 2003.Understanding plant responses to drought-from genes to the whole plant. Funct. Plant Biol. 30: 239-264.

Cho MH, Jang A, Bhoo SH, Jeon JS, Hahn TR. 2012. Manipulation of triose phosphate/phosphate translocator and cytosolic fructose-1,6-bisphosphatase, the key components in photosynthetic sucrose synthesis, enhances the source capacity of transgenic Arabidopsis plants. Photosynth. Res. 111: 261-268.

Danby RK, Hik DS. 2007. Responses of white spruce (Picea glauca) to experimental warming at a subarctic alpine treeline. Global Change Biol. 13: 437-451.

Heath R, Packer L. 1968. Photoperoxidation in isolated chloroplast I. Kinetics and stoichimetry of fatty acid peroxidation. Arch. Biochem. Biophys. 125: 189-198.

IPCC. 2007. Climate change 2007: the physical science basis: summary for policymakers. Cambridge University Press. Cambridge. UK.

Jain R, Srivastava S, Solomon S, Shrivastava AK, Chandra A. 2010. Impact of excess zinc on growth parameters, cell division, nutrient accumulation, photosynthetic pigments and oxidative stress of sugarcane (Saccharum spp.). Acta Physiol. Plant. 32: 979-986.

Kautsky H, A Hirsch. 1931. Neue Versuche zur Kohlens aureassimilation. Naturwissenschaften 19: 964.

Kim YS, Ko SC, Oh BY. 1981. Distribution Atlas of Plants of Korea (5) Atlas of Quercus in Korea. Univ. Korea, Seoul, Korea. 93-133.

Korea Forest Research Institute. 1996. Broad leaf tree resource survey report. Korean Forest Research Institute.

Kriedemann P E, Graham RD, Wiskich JT. 1985. Photosynthetic dysfunction and in vivo changes in chlorophyll a fluorescence from manganese-deficient wheat leaves, Aust. J. Agric. Res. 36: 157-169.

Kwon KW, Choi JH, Song HK. 2002. Studies on regeneration strategy establishment of oak species -Biomass production, sprouts and their growth of Quercus mongolica, Quercus variabilis and Quercus acutissima. KFS annual Report, Seoul, Korea, pp.177-179.

$\mathrm{Lu}$ Y, Sharkey TD. 2004. The role of amylomaltase in maltose metabolism in the cytosol of photosynthetic cells. Planta 218: 466-473.

Ponton S, Dupouey JL, Bréda N, Dreyer E. 2002. Comparison of water-use efficiency of seedlings from two sympatric oak species: genotype $\times$ environment interactions. Tree 
Physiol. 22: 413-422.

Reynolds RW, TM Smith, C Liu, DB. Chelton, KS Casey, MG. Schlax. 2007. Daily High-resolution Blended Analyses for sea surface temperature. J. Climate 20: 5473-5496.

Ritchie GA. 1984. Assessing seedling quality, p. 243-259. In: ML. Duryea, TD. Landis (eds.). Forest Nursery Manual 1: Production of Bareroot Seedlings, Martinus Nijhoff Publishers, etherlands.

Roussel M, Le Thiec D, Montpied P, Ningre N, Guehl JM, Brendel O. 2009 Diversity of water use efficiency among Quercus robur genotypes: contribution of related leaf traits. Ann. For. Sci. 66: 408-408.

Sagardoy R, Morales F, López-Millán AF, Abadia A, Abadia J. 2009. Effects of zinc toxicity on sugar beet (Beta vulgaris $\mathrm{L}$.) plants grown in hydroponics. Plant Biol. 11: 339-350.

Shinozaki K, Yamaguchi-Sinozaki K. 2007. Gene networks involved in drought stress response and tolerance. J. Exp. Bot. 58: 221-227.

Sibley JL, Eakes DJ, Gilliam CH, Keever GJ, Dozier Jr WA, Himelrick DG. 1996. Foliar SPAD-502 meter values, nitrogen levels, and extractable chlorophyll for red maple selections. HortScience 31: 468-470.
Stitt, M., Lilley, RMC, Gerhardt R, Heldt HW. 1989. Determination of metabolite levels in specific cells and subcellular compartments of plant leaves. Method Enzymol. 174: 518-522.

Sung HI, Song KS, Cha YG, Kim JJ. 2011. Characteristics of growth and seedling quality of 1-year-old container seedlings of Quercus myrsinaefolia by shading and fertilizing treatment. J. Korean For. Soc. 100: 598-608.

Switzer GL, Nelson LE. 1963. Effects of nursery fertility and density on seedling characteristics yield, and field performance of lobloly pine (Pinus taeda L.). Soil Sci. Soc. Amer. Proc. 27: 461-464.

Tyler CM, B Kuhn, FW Davis. 2006. Demography and recruitment limitations of three oak species in California. Quarterly Review of Biology 81: 127-152.

Walters RG, Ibrahim DG, Horton P, Kruger NJ. 2004. A mutant of Arabidopsis lacking the triose-phosphate/ phosphate translocator reveals metabolic regulation of starch breakdown in the light. Plant Physiol. 135: 891-906.

Zhao C, Liu Q. 2009. Growth and photosynthetic responses of two coniferous species to experimental warming and nitrogen fertilization. Can J. For. Res. 39: 1-11. 